\title{
Older Adult Self Report Construct and Criterion Validity Evidence for the Brazilian Elderly
}

\author{
Camila Rosa de Oliveira ${ }^{1}$, Luis Henrique Paloski ${ }^{1}$, Marianne Farina ${ }^{2}$, Valéria Gonzatti ${ }^{2}$, Adriano Medeiros Cunha ${ }^{2}$, \\ Manoela Ziebell de Oliveira ${ }^{2}$, Irani Iracema de Lima Argimon ${ }^{2}$, and Tatiana Quarti Irigaray ${ }^{2 *}$ \\ ${ }^{1}$ Faculdade Meridional - IMED (Brazil) \\ ${ }^{2}$ Pontifícia Universidade Católica do Rio Grande do Sul (Brazil)
}

\begin{abstract}
Título: Evidencia de validez de criterio y de constructo del Older Adult Self Report para ancianos brasileños.

Resumen: En Brasil, el número de instrumentos científicos validados y reconocidos para la evaluación clínica de las personas de adultos mayores es limitado. El Autoinforme del Adulto Mayor (OASR) es una escala de evaluación psicopatológica de las personas con más de 60 años, que evalúa el funcionamiento adaptativo y la psicopatología. El objetivo de este estudio fue investigar el constructo OASR y buscar evidencia de la validez de criterio para adultos mayores brasileños. La muestra incluyó a 345 individuos, entre 60 y 94 años de edad, que fueron reclutados por conveniencia. Los participantes respondieron a un cuestionario que contenía preguntas sobre informaciones demográficas y de salud, y también el Examen Mini del Estado Mental, la Escala de Depresión Geriátrica versión corta y la OASR Los datos se analizaron mediante estadística descriptiva, análisis de correlación y discriminante de Pearson. Los resultados mostraron asociaciones significativas entre las subescalas de OASR, evidenciando correlación con la capacidad cognitiva general y síntomas depresivos. Además, OASR fue sensible para identificar a adultos mayores con síntomas significativos de depresión. En conclusión, el OASR mostró evidencia adecuada de constructo y la validez de criterio para una muestra de ancianos brasileños.

Palabras clave: Vejez; psicopatología; validez de constructo; validez de criterio; cognición
\end{abstract}

Abstract: In Brazil, the number of validated and recognized scientific instruments for clinical evaluation of elderly persons is limited. The Older Adult Self-Report (OASR) is a psychopathological rating scale for persons with more than 60 years, which evaluates adaptive functioning and psychopathology. The aim of this study was at investigating OASR construct and criterion validity evidence for Brazilian elderly. The sample included 345 individuals, between 60 and 94 years of age, which were recruited by convenience. Participants responded to a questionnaire containing questions about demographic and health information, the Mini Mental State Examination, the Geriatric Depression Scale short version and the OASR. Data were analyzed using descriptive statistics, Pearson's correlation and discriminant analysis. The results showed significant associations between the scores of OASR's subscales, correlating with general cognitive ability and depressive symptoms. Furthermore, OASR was sensitive to identify elderly with significant symptoms of depression. In conclusion, the OASR showed adequate evidence of construct and criterion validity for a sample of Brazilian elderly.

Key words: Elderly; Psychopathology; Construct validity; Criterion validity; Cognition.

\section{Introduction}

Internationally, there is a variety of qualified psychometric instruments for the psychological assessment of the elderly (Vega \& Newhouse, 2014). There is more than one hundred psychopathological assessment tests and scales for individuals over 60 years of age (Achenbach, Newhouse, \& Rescorla, 2004; Brigidi, Achenbach, Dumenci, \& Newhouse, 2010), and some of these instruments are self-administered or answered by informants. It is estimated that by the year 2050 the number of elderly will exceed two billion (WHO, 2015), for this reason, there is a clear need for valid, reliable and standardized instruments for the elderly. In Brazil, the number of validated and recognized scientific instruments for clinical evaluation of elderly persons is limited (Werlang, 2012).

The Older Adult Self-Report (OASR) is a psychopathological rating scale for persons aged over 60 years (Ali \& Cagle, 2014) and is one of the scales of the Achenbach System of Empirically Based Assessment - ASEBA (Achenbach, 2006). The ASEBA is an empirically based research system most commonly used in clinical practice and research
(Achenbach \& Rescorla, 2007; Rocha, Araújo, \& Silvares, 2008). Studies with the ASEBA scales in Brazil are incipient, considering that not all instruments are validated (Emerich, Monzani, \& Silvares, 2010). The OASR consists of several subscales that investigate adaptive functioning (e.g., relationship, personal care and daily living skills) and psychopathology (such as anxiety, depression and memory problems). Despite its broad scope the OASR does not provide a diagnosis, but quantifies symptoms that guide to further evaluate these aspects (Achenbach et al., 2004).

In the Brazilian context, the other scales of ASEBA have already been cross-culturally adaptated and validited through studies (Bordin et al., 2013). However, there are no studies that validite OASR in national and international literature. Therefore, the aim of this study was to investigate OASR's construct and criterion validity evidence for the Brazilian elderly. 


\section{Method}

\section{Design}

Cross-sectional study.

\section{Participants}

The sample included 345 individuals, between 60 and 94 years of age $(M=69.47$; $S D=6.73)$, recruited by convenience, with years of study between one and $25(M=11.15$; $S D=5.03)$. The distribution according to gender was 50 $(15 \%)$ men and 295 (85\%) women. Elderly persons with scores below the cut-off point in the Mini-Mental State Examination - MMSE (adapted by Chaves \& Izquierdo, 1992) were excluded $(<22$ to five years of schooling, $<23$ between six and 11 years and $<24$ to 12 years or more, according to Kochhann, Varela, Lisboa, \& Chaves, 2010). Moreover, the elderly who had non-corrected primary sensory problems and the ones who had diagnosis of neurological or psychiatric disorders were also excluded.

\section{Procedures and Instruments}

The study was approved by the Ethics Committee of the Pontificia Universidade Católica do Rio Grande do Sul (CAAE 12490013.2.0000.5336). Written informed consent was obtained from each participant. The elderly were individually assessed and responded to demographic and health questionnaires (age, education, gender, socioeconomic status and clinical history), the MMSE, the Geriatric Depression Scale short version (GDS-15) and the OASR. The MMSE (adapted by Chaves \& Izquierdo, 1992) is a cognitive screening that evaluates temporal and spatial orientation, immediate memory, attention/concentration, delayed recall and language, whose scores range from 0 to 30 . The GDS-15 consists of 15 questions related to the occurrence ('yes' or 'no') of depressive symptoms and their items may be grouped into three factors: Humor, Motivation and Positive Affect (Shahnawaz et al., 2013). Scores range from 0 to 15 and the cut-off point to indicate significant symptoms of depression is $\geq 6$.

The OASR is a self-report instrument consisting of 123 items distributed in three scales: 1) Adaptive Functioning, which includes the Friends, Spouse/Partner and Personal Strengths subscales; 2) Empirically Based, which includes the Anxious/Depressed, Worries, Somatic Complaints, Functional Impairment, Memory/Cognition, Thought Problems, Irritable/Disinhibited and Total Problems subscales; and 3) Critical Items - DSM-Oriented, which includes the Depressive Problems, Anxiety Problems, Somatic Problems, Dementia Problems, Psychotic Problems and Antisocial Personality Problems subscales. Each question receives a score according to the occurrence of symptoms in the last two months ( 0 for not true; 1 for somewhat or sometimes true; and 2 for very true or often true).

\section{Data analysis}

Descriptive statistics as mean, standard deviation, percentages and percentiles were used. The distribution of data was investigated by the Kolmogorov-Smirnov test. The association between all the OASR scores, and the raw scores of OASR subscales with cognitive assessment (raw score of MMSE and its items) and mood (raw score of GDS-15 and its factors) was made through the Pearson correlation. We performed a stepwise discriminant analysis with Wilk's lambda in order to verify the if the scores of subscales of OASR could help discriminate groups of participants based on the presence or absence of depressive symptoms. The assumptions of normality and homogeneity of variancecovariance matrices from each group were tested, respectively, with the Shapiro-Wilk test and the M Box test. Level of significance was set at $p \leq 0.05$, and the statistical package used was the SPSS version 22 for Windows.

\section{Results}

Results of the correlation analysis are presented in Table 1. The Adaptive Functioning scale variables presented positive associations with each other (except between the Friends and Spouse/Partner subscales), and the variables of the Empirically Based and Critical Items scales, with positive and negative correlations, ranging from weak to moderate. The variables of Empirically Based scale were associated positively with each other and with the variables of Critical Items scale, showing mostly moderate and strong correlations. Finally, scores of Critical Items scale correlated positively with each other (moderate and strong associations).

The associations between scores of the OASR scales, MMSE and GDS-15 scores are presented in Table 2. Regarding the total score of the MMSE, there were negative associations with Empirically Based scale (Anxious/Depressed, Memory/Cognition, Thought Problems and Total Problems subscales) and Critical Items scale (Depressive Problems, Anxiety Problems and Dementia Problems subscales). When analyzing the cognitive functions of MMSE, negative associations were found between Language score and Adaptive Functioning scale (Personal Strenghts subscale), Attention/Concentration score and Empirically based scale (Anxious/Depressed subscale), Delayed Recall score and Empirically based scale (Memory/Cognition subscale), Spatial Orientation score and Critical Items scale (Dementia Problems subscale), and Attention/Concentration score and Critical Items scale (Psychotic Problems subscale). 
Table 1. Pearson correlation between the scores of OASR.

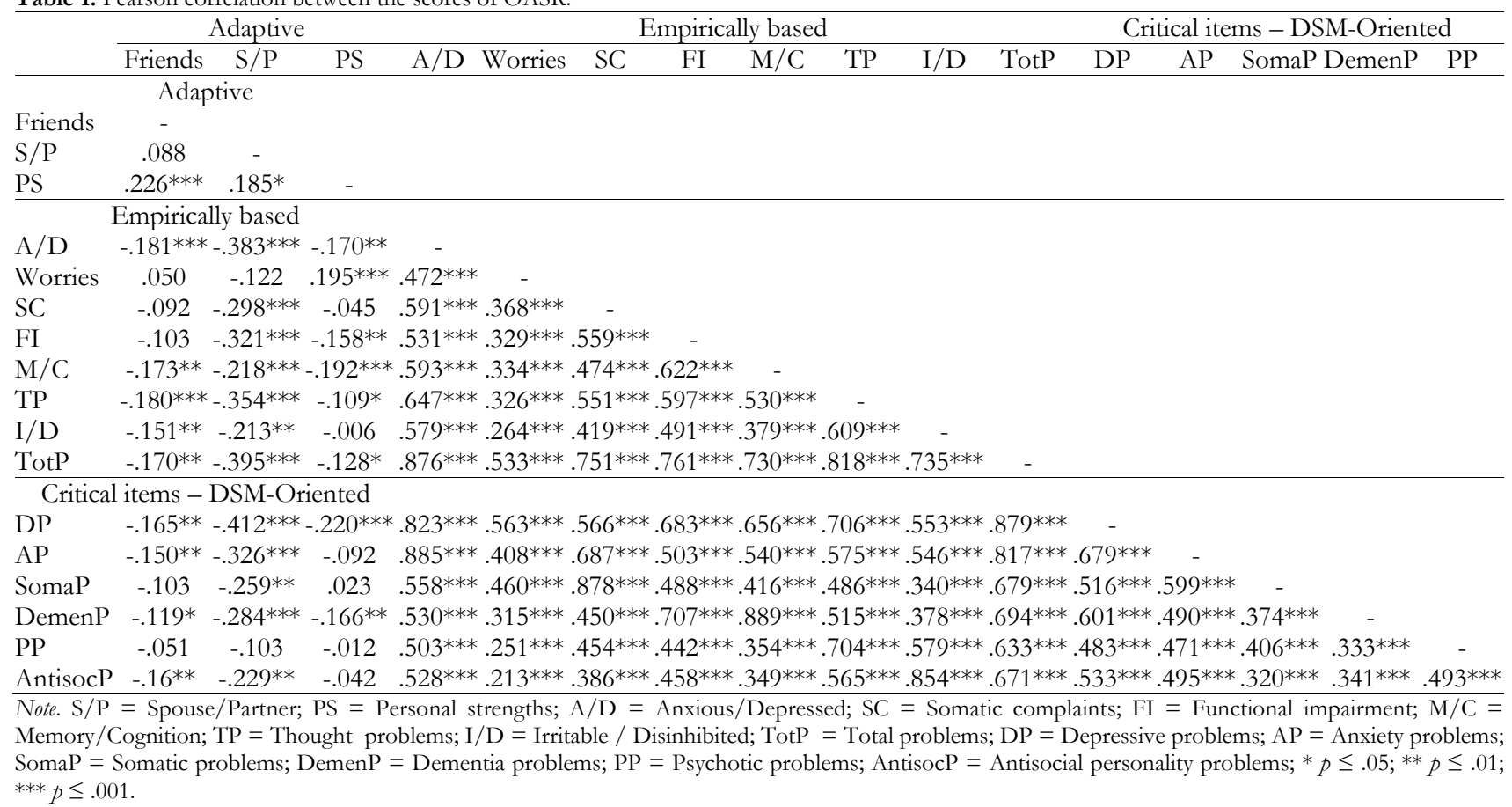

Table 2. Correlations between the OASR scales with the MMSE and the GDS-15 Scores.

\begin{tabular}{|c|c|c|c|c|c|c|c|c|c|c|c|}
\hline \multirow{2}{*}{ OASR scales } & \multicolumn{7}{|c|}{ MMSE } & \multicolumn{4}{|c|}{ GDS-15 } \\
\hline & Total & TO & $\mathrm{SO}$ & IM & $\mathrm{A} / \mathrm{C}$ & DR & $\mathrm{L}$ & Total & Humor & Motivation & Positive affect \\
\hline \multicolumn{12}{|l|}{ Adaptive } \\
\hline Friends & -.02 & -.01 & -.06 & -.00 & -.06 & -.01 & .01 & $-.18 * * *$ & -.10 & $-.13 *$ & $-.19 * *$ \\
\hline Spouse/Partner & .14 & -.00 & .07 & .00 & .16 & .10 & -.04 & $-.25 * *$ & -.20 & $-.28 *$ & -.14 \\
\hline Personal strengths & .03 & .09 & .06 & -.04 & .08 & -.04 & $-.12 *$ & $-.28 * * *$ & $-.19 * *$ & $-.25 * * *$ & $-.27 * * *$ \\
\hline \multicolumn{12}{|l|}{ Empirically based } \\
\hline Anxious/Depressed & $-.13^{*}$ & .02 & -.07 & -.08 & $-.11 *$ & -.09 & -.02 & $.51 * * *$ & $.50 * * *$ & $.32 * * *$ & $.35^{* * *}$ \\
\hline Worries & -.01 & .07 & .00 & .01 & .05 & -.07 & -.08 & $.23 * * *$ & $.27 * * *$ & .11 & $.15^{*}$ \\
\hline Somatic complaints & -.05 & .06 & -.03 & .00 & -.08 & -.04 & -.01 & $.34 * * *$ & $.38 * * *$ & $.32 * * *$ & $.20 * * *$ \\
\hline Functional impairment & -.09 & .03 & -.09 & .00 & -.09 & -.02 & -.06 & $.37 * * *$ & $.37 * * *$ & $.37 * * *$ & $.28 * * *$ \\
\hline Memory/Cognition & $-.11 *$ & -.02 & -.09 & -.04 & -.01 & $-.12^{*}$ & -.03 & $.40^{* * *}$ & $.41 * * *$ & $.33^{* * *}$ & $.24 * * *$ \\
\hline Thought problems & $-.13^{*}$ & -.03 & -.08 & .06 & -.09 & -.05 & -.06 & $.41 * * *$ & $.43^{* * *}$ & $.35^{* * *}$ & $.30 * * *$ \\
\hline Irritable/Disinhibited & .01 & .01 & -.01 & -.03 & -.03 & .04 & .01 & $.20 * * *$ & $.20 * *$ & $.13^{*}$ & $.14^{*}$ \\
\hline Total problems & $-.11 *$ & .02 & -.07 & -.03 & -.08 & -.07 & -.04 & $.48^{* * *}$ & $.49 * * *$ & $.37 * * *$ & $.33 * * *$ \\
\hline \multicolumn{12}{|l|}{ Critical items - DSM-Oriented } \\
\hline Depressive problems & $-.12 *$ & -.03 & -.06 & -.01 & -.10 & -.04 & -.05 & $.50 * * *$ & $.48^{* * *}$ & $.37 * * *$ & $.38 * * *$ \\
\hline Anxiety problems & $-.11 *$ & .03 & -.08 & -.06 & -.09 & -.06 & -.08 & $.40^{* * *}$ & $.44^{* * *}$ & $.28^{* * *}$ & $.25 * * *$ \\
\hline Somatic problems & -.01 & .08 & -.03 & -.02 & -.01 & -.04 & -.02 & $.33 * * *$ & $.35^{* * *}$ & $.25^{* * *}$ & $.22 * * *$ \\
\hline Dementia problems & $-.11 *$ & -.00 & $-.11 *$ & -.01 & -.06 & -.09 & -.05 & $.36 * * *$ & $.39 * * *$ & $.31 * * *$ & $.24 * * *$ \\
\hline Psychotic problems & -.10 & -.05 & .00 & .01 & $-.11 *$ & -.03 & -.01 & $.27 * * *$ & $.32 * * *$ & $.19 * *$ & $.19 * *$ \\
\hline Antisocial personality problems & -.03 & -.02 & .01 & -.01 & -.05 & .02 & -.04 & $.14^{* *}$ & .12 & $.13^{*}$ & $.15^{*}$ \\
\hline
\end{tabular}

Note. MMSE $=$ Mini Mental State Examination; TO $=$ Temporal orientation; SO = Spacial orientation; IM = Immediate memory; A/C = Attention/Concentration; DR $=$ Delayed recall; $\mathrm{L}=$ Language; GDS-15 = Geriatric Depression Scale, version of 15 points; * $p \leq .05 ; * * p \leq .01 ; * * * p \leq .001$.

The GDS-15 total score had a negative association with all variables in the Adaptive scale, and positive associations with all variables in the Empirically Based and the Critical Items scales. The Humor, Motivation and Positive Affect factors of the GDS-15 showed positive associations with most of the subscales of the OASR. Table 3 shows the comparison of sociodemographic characteristics, cognitive status, depressive symptoms and the OASR scores between clinical and non-clinical groups as cutoff point in the GDS15. 
Table 3. Comparison of Sociodemographic Characteristics, Cognitive Status, Depressive Symptoms and OASR Scales among Clinical and Non-clinical Groups.

\begin{tabular}{|c|c|c|c|c|}
\hline & Clinical group & Nonclinical group & $F / \chi^{2}$ & $p$ \\
\hline Age & $68.43 \pm 6.01$ & $69.80 \pm 6.93$ & .612 & .108 \\
\hline Education & $1.70 \pm 4.48$ & $11.29 \pm 5.19$ & 4.062 & .318 \\
\hline \multicolumn{5}{|l|}{ Gender } \\
\hline Female $(\%)$ & 85.50 & 85.50 & \multirow{2}{*}{.000} & \multirow{2}{*}{.992} \\
\hline Male $(\%)$ & 14.50 & 14.50 & & \\
\hline \multicolumn{5}{|l|}{ MMSE } \\
\hline Temporal orientation & $4.84 \pm .43$ & $4.86 \pm .48$ & .141 & .793 \\
\hline Spatial orientation & $4.92 \pm .32$ & $4.93 \pm .29$ & .406 & .751 \\
\hline Immediate memory & 2.99土.11 & $2.99 \pm .09$ & .565 & .707 \\
\hline Attention/Concentration & $4.52 \pm 1.06$ & $4.44 \pm 1.11$ & .764 & .550 \\
\hline Delayed recall & $1.64 \pm 1.13$ & $1.71 \pm 1.07$ & 1.532 & .582 \\
\hline Language & $8.84 \pm .40$ & $8.78 \pm .56$ & 3.906 & .276 \\
\hline Total & $27.70 \pm 1.67$ & $27.70 \pm 1.90$ & 1.535 & .999 \\
\hline \multicolumn{5}{|l|}{ GDS-15 } \\
\hline Humor & $3.23 \pm 1.42$ & $1.37 \pm .74$ & 34.166 & $\leq .001$ \\
\hline Motivation & $2.08 \pm .93$ & $.66 \pm .74$ & .850 & $\leq .001$ \\
\hline Positive affect & $1.21 \pm 1.15$ & $.15 \pm .44$ & 121.938 & $\leq .001$ \\
\hline Total & $7.86 \pm 2.11$ & $2.56 \pm 1.37$ & 16.622 & $\leq .001$ \\
\hline \multicolumn{5}{|l|}{ OASR scales } \\
\hline \multicolumn{5}{|l|}{ Adaptive } \\
\hline Friends & $8.15 \pm 2.25$ & $9.22 \pm 2.06$ & 1.685 & $\leq .001$ \\
\hline Spouse/Partner & $4.21 \pm 2.43$ & $5.41 \pm 2.32$ & .882 & .006 \\
\hline Personal strengths & $27.39 \pm 6.10$ & $31.00 \pm 5.24$ & 4.442 & $\leq .001$ \\
\hline \multicolumn{5}{|l|}{ Empirically based } \\
\hline Anxious/Depressed & $16.47 \pm 7.90$ & $9.32 \pm 5.91$ & 17.531 & $\leq .001$ \\
\hline Worries & $9.24 \pm 2.84$ & $8.05 \pm 2.40$ & 1.807 & $\leq .001$ \\
\hline Somatic complaints & $6.96 \pm 5.62$ & $4.39 \pm 3.84$ & 15.774 & $\leq .001$ \\
\hline Functional impairment & $5.45 \pm 3.69$ & $3.29 \pm 2.75$ & 11.512 & $\leq .001$ \\
\hline Memory/Cognition & $1.00 \pm 3.48$ & $7.28 \pm 3.42$ & .263 & $\leq .001$ \\
\hline Thought problems & $6.98 \pm 4.33$ & $3.79 \pm 3.14$ & 1.275 & $\leq .001$ \\
\hline Irritable/Disinhibited & $8.87 \pm 5.14$ & $6.62 \pm 4.95$ & .282 & $\leq .001$ \\
\hline Total problems & $7.48 \pm 28.40$ & $46.47 \pm 21.80$ & 11.692 & $\leq .001$ \\
\hline \multicolumn{5}{|l|}{ Critical items - DSM-Oriented } \\
\hline Depressive problems & $11.71 \pm 5.96$ & $6.75 \pm 4.31$ & 18.428 & $\leq .001$ \\
\hline Anxiety problems & $7.72 \pm 4.05$ & $4.99 \pm 3.43$ & 4.409 & $\leq .001$ \\
\hline Somatic problems & $4.28 \pm 3.31$ & $2.71 \pm 2.20$ & 17.402 & $\leq .001$ \\
\hline Dementia problems & $7.41 \pm 3.00$ & $5.47 \pm 2.71$ & 2.588 & $\leq .001$ \\
\hline Psychotic problems & $1.72 \pm 1.84$ & $.94 \pm 1.22$ & 2.875 & $\leq .001$ \\
\hline Antisocial personality problems & $3.70 \pm 2.38$ & $2.99 \pm 2.31$ & .808 & .016 \\
\hline$n$ & 83 & 262 & & \\
\hline
\end{tabular}

The groups did not differ significantly with respect to age, education, gender and general cognitive ability. However, the clinical group had higher scores on the total score of the GDS-15, as well as its factors, and in all subscales of OASR. The stepwise discriminant analysis extracted one discriminant function, retaining the scores of four subscales as statistically significant (Anxious/Depressed, Thought Problems, Personal Strengths and Antisocial Personality Problems), explaining approximately $51 \%$ of the variability between groups $\left(\Lambda=0.661 ; \chi^{2}(4)=57.095 ; p \leq 0,001\right)$. Table 4 shows the standardized coefficients of the subscales included in the discriminant function.
Table 4. Coefficients of the Discriminant Function.

\begin{tabular}{lc}
\hline OASR subscales & $\begin{array}{c}\text { Coefficients of the } \\
\text { discriminant function }\end{array}$ \\
\hline Anxious/Depressed & .116 \\
Thought Problems & .185 \\
Personal Strengths & -.052 \\
Antisocial Personality Problems & -.200 \\
Constant & 1.177 \\
Eigenvalue & .512 \\
\hline
\end{tabular}

Table 5 presents the classification statistics. The percentage of elderly classified correctly was $82.60 \%$. 
Table 5. Classification Results through Discriminatory Function.

\begin{tabular}{lccc}
\hline \multirow{2}{*}{ Original group } & \multicolumn{3}{c}{ Predict group } \\
\cline { 2 - 3 } & $\begin{array}{c}\text { Clinical group Non-clinical group } \\
n(\%)\end{array}$ & $n(\%)$ & \\
\hline Clinical group $n(\%)$ & $50(6.20)$ & $33(39.80)$ & 83 \\
Non-clinical group $n(\%)$ & $27(1.30)$ & $235(89.70)$ & 262 \\
\hline
\end{tabular}

\section{Discussion and Conclusions}

The main purpose of this study was to provide evidence of the validity of OASR for Brazilian elderly. The OASR demonstrated significant associations between the scores of its subscales, correlating with general cognitive ability and depressive symptoms. Furthermore, OASR was sensitive enough to identify elderly with significant symptoms of depression. There were significant associations between most of the subscales' scores, suggesting adequate internal consistency. The results corroborate the study by Achenbach et al. (2004), in which items comprising the Older Adult Behavior Checklist (OABCL) and OASR scales showed Cronbach alphas between .66 to .97 and .63 to .96 , respectively.

Associations between scores of the OASR scales, MMSE and GDS-15 scores are presented in Table 2. Regarding the total score of the MMSE, there were negative associations with Empirically Based scale (Anxious/Depressed, Memory/Cognition, Thought Problems and Total Problems subscales) and Critical Items scale (Depressive Problems, Anxiety Problems and Dementia Problems subscales). When analyzing the cognitive functions of MMSE, there were negative associations between Language score and Adaptive Functioning scale (Personal Strengths subscale), Attention/Concentration score and Empirically based scale (Anxious/Depressed subscale), Delayed Recall score and Empirically based scale (Memory/Cognition subscale), Spatial Orientation score and Critical Items scale (Dementia Problems subscale), and Attention/Concentration score and Critical Items scale (Psychotic Problems subscale).

In construct validity analysis, regarding the cognitive functioning and OASR scores, elderly with high scores on the MMSE had a lower incidence of anxiety and depression, and fewer cognitive complaints, thinking problems and symptoms of dementia. Moreover, on an isolated analysis of cognitive functions evaluated by MMSE, it was observed that low scores for spatial orientation are associated with higher dementia symptoms. Attentional problems on the MMSE were associated with anxiety and psychotic symptoms, and mnemonic deficits correlated with subjective memory complaints. Accordingly, it can be inferred that the OASR was sensitive in detecting cognitive deficits present in dementia. Maruish (2004) corroborates this finding, indicating a positive correlation between the MMSE and the OASR scores.

Hayen and colleagues (2011) suggest a cognitive heterogeneity in the elderly and a relationship between depression and cognition (Sengupta \& Benjamin, 2015; Wang, \& Blazer,
2015). There is a prevalence of mood disorders in the elderly (Cartaxo, Gaudêncio, \& Lacerda, 2011; Weber et al, 2012), especially depression (Novick et al., 2015). Regarding cognitive deficits, episodic memory and temporal-spatial orientation are the main functions associated with the development of psychopathology in individuals over 60 years of age (Wang \& Blazer, 2015). Subjective cognitive complaints are influenced by the elderly awareness about the impact of cognitive impairment in functional ability (Salem, Vogel, Ebstrup, Linneberg, \& Waldemar, 2015).

The GDS-15 scores presented associations with all subscales of the OASR. Discriminant analysis showed that OASR was sensitive enough to detect both elderly with or without significant depressive symptoms, correctly diagnosing $82.60 \%$ of them through the Anxious/Depressed, Thought Problems, Personal Strengths and Antisocial Personality Problems subscales. Compared to the study of Brigidi and colleagues (2010), the Memory/Cognition and Anxious/Depressed subscales of the OACBL and the MMSE correctly identified $84 \%$ of older adults with mood disorder. The occurrence of depression can impact cognitive abilities of the elderly as well as affect the performance in daily life activities and social life (Baiyewu, Yusuf, \& Ogundele, 2015; Stoeckel \& Litwin, 2015). Furthermore, depression is a comorbid diagnostic for other psychopathological disorders.

According to the results, only the Anxious/Depressed, Thought Problems, Personal Strengths and Antisocial Personality Problems subscales were significant to discriminate elderly with and without depressive symptoms. These scales assess, mainly, mood, somatic complaints, functional ability and personality. In contrast, in the study by Brigidi and colleagues (2010), the Memory/Cognition and Anxious/Depressed subscales differentiated the elderly with and without depressive symptoms. In our study, this result may have occurred precisely because the elderly are the ones who answered OASR, not the informant, which emphasizes items related to the perception of internal changes rather than external, as in OABCL.

Adaptive functioning is related to the development of psychopathology in elderly (Achenbach et al., 2004; Brigidi et al, 2010). The parallel administration of these two instruments - OASR and OABCL - provides standardized data on the elderly, and also considers the evaluation of family members or caregivers (Brigidi et al,, 2010). Other instruments have shown that failures in adaptive functioning affect mental health and quality of life in aging (Lai et al., 2014).

In conclusion, the OASR showed adequate evidence of construct and criterion validity for a sample of Brazilian elderly. It is important to investigate psychometric characteristics of self-report scales for psychopathology evaluation in the Brazilian context, especially for the elderly population. However, this study had some limitations. Clinical samples with psychiatric or neurocognitive disorders were not included. The lack of studies for comparison is also a critical 
factor. Data from OASR were not compared to the family reports. Often, there is discrepancy between the results obtained from self-reported instruments and those obtained from other informants. Psychopathology assessment should consider the perception of the elderly and their families/caregivers, providing accurate and cohesive data

\section{References}

Achenbach, T. M. (2006). As others see us clinical and research implications of cross-informant correlations for psychopathology. Current Directions in Psychological Science, 15(2), 94-98. doi: 10.1111/j.09637214.2006.00414.x

Achenbach, T. M., \& Rescorla, L. (2007). Multicultural understanding of child and adolescent psychopathology: Implications for mental health assessment. Guilford Press.

Achenbach, T.M., \& Rescorla, L.A. (2003). Manual for the ASEBA Adult Forms \& Profiles. Burlington, VT: University of Vermont, Research Center for Children, Youth, and Families.

Achenbach, T.M., Newhouse, P.A., \& Rescorla, L.A. (2004). Manual for the ASEBA Older Adult Forms \& Profiles. Burlington, VT: University of Vermont, Research Center for Children, Youth, and Families.

Ali, N., \& Cagle, S. (2014). Psychological Health in Adults with Morquio Syndrome. JIMD Reports, 20, 87-93. doi: 10.1007/8904_2014_396

Almeida, O.P., \&. Almeida, S.A. (1999). Confiabilidade da versão brasileira da Escala de Depressão em Geriatria (GDS) versão reduzida. Arquivos de Neuro-Psiquiatria, 57(2B): 421-426. doi: 10.1590/S0004282X1999000300013

Baiyewu, O., Yusuf, A. J., \& Ogundele, A. (2015). Depression in elderly people living in rural Nigeria and its association with perceived health, poverty, and social network. International Psychogeriatrics, 12, 1-7.

Bordin, I. A., Rocha, M. M., Paula, C. S., Teixeira, M. C. T. V., Achenbach, T. M., Rescorla, L. A., \& Silvares, E. F. M.. (2013). Child Behavior Checklist (CBCL), Youth Self-Report (YSR) and Teacher's Report Form (TRF): an overview of the development of the original and Brazilian versions. Cadernos de Saúde Pública, 29(1), 13-28. doi: 10.1590/S0102-311X2013000100004

Brigidi, B. D., Achenbach, T. M., Dumenci, L., \& Newhouse, P. A. (2010). Broad spectrum assessment of psychopathology and adaptive functioning with the Older Adult Behavior Checklist: a validation and diagnostic discrimination study. International Journal of Geriatric Psychiatry, 25(11), 1177-1185. doi: 10.1002/gps.2459

Cartaxo, H. G., Gaudêncio, M. M. P., \& da Silva Lacerda, G. (2011). Caracterização de idosos sintomáticos ou portadores de afecções neuropsiquiátricas segundo cuidadores familiares. Cogitare Enfermagem, 16(2), 319325. doi: 10.5380/ce.v16i2.21821

Chaves, M. L. F., \& Izquierdo, I. (1992), Differential diagnosis between dementia and depression: a study of efficiency increment. Acta Neurologica Scandinavica, 85, 378-382. doi: 10.1111/j.1600-0404.1992.tb06032.x

Emerich, D. R., Rocha, M. M., \& Silvares, E. F. M. (2010). Estudo de validação preliminar do "Inventário dos Comportamentos de Criancas e Adolescentes de 6 18 anos" (CBCL/6-18), versão brasileira do Child Behavior Checklist. Projeto de Pesquisa submetido ao Comitê de Ética em Pesquisas com Seres Humanos do Instituto de Psicologia da Universidade de São Paulo.

Hayden, K. M., Reed, B. R., Manly, J. J., Tommet, D., Pietrzak, R. H., Chelune, G. J., ... \& Jones, R. N. (2011). Cognitive decline in the elderly: an
(Achenbach et al., 2004; Achenbach, 2006). Future studies should expand the sample size and include clinical groups in order to investigate the clinical applicability of OASR, as well as reliability and the establishment of normative data for diagnosis.

analysis of population heterogeneity. Age and ageing, 40(6), 684-689. doi: 10.1093/ageing/afr101

Kochhann, R., Varela, J., Lisboa, C.S.M. \& Chaves, M.L. (2010). The Mini Mental State Examination Review of cut-off points adjusted for schooling in a large Southern Brazilian sample. Dementia \& Neuropsychologia, 4(1), 35-41.

Lai, C. Y., Zauszniewski, J. A., Tang, T. C., Hou, S. Y., Su, S. F., \& Lai, P. Y. (2014). Personal beliefs, learned resourcefulness, and adaptive functioning in depressed adults. Journal of Psychiatric Mental Health Nursing, 21(3), 280-287. doi: 10.1111/ipm.12087

Maruish, M. E. (2004). The use of psychological testing for treatment planning and outcomes assessment. Volume 3: Instruments for adults. Mahwah, US: Lawrence Erlbaum Associates Publishers.

Novick, D., Hong, J., Montgomery, W., Dueñas, H., Gado, M., \& Haro, J. M. (2015). Predictors of remission in the treatment of major depressive disorder: real-world evidence from a 6-month prospective observational study. Neuropsychiatric Disease and Treatment, 11, 197. doi: $10.2147 /$ NDT.S75498

Rocha, M., Araújo, L. G. S., \& Silvares, E. F. M. (2008). Um estudo comparativo entre duas traduções brasileira do Inventário de Auto-Avaliação para Jovens (YSR). Psicologia: Teoria e Prática, 10, 14-24.

Salem, L. C., Vogel, A., Ebstrup, J., Linneberg, A., \& Waldemar, G. (2015). Subjective cognitive complaints included in diagnostic evaluation of dementia helps accurate diagnosis in a mixed memory clinic cohort. International Journal of Geriatric Psychiatry, 17. doi: 10.1002/gps.4272

Sengupta, P., \& Benjamin, A. I. (2015). Prevalence of depression and associated risk factors among the elderly in urban and rural field practice areas of a tertiary care institution in Ludhiana. Indian Journal of Public Health, 59(1), 3. doi: 10.4103/0019-557X.152845

Shahnawaz, Z., Reppermund, S., Brodaty, H., Crawford, J. D., Draper, B., Trollor, J. N., \& Sachdev, P. S. (2013). Prevalence and characteristics of depression in mild cognitive impairment: the Sydney Memory and Ageing Study. Acta Psychiatrica Scandinavica, 127(5), 394-402. doi: $10.1111 /$ acps. 12008

Stoeckel, K. J., \& Litwin, H. (2015). The impact of social networks on the relationship between functional impairment and depressive symptoms in older adults. International Psychogeriatrics, 6, 1-9.

Vega, J. N., \& Newhouse, P. A. (2014). Mild Cognitive Impairment: diagnosis, longitudinal course, and emerging treatments. Current Psychiatry Reports, 16(10), 1-11. doi: 10.1007/s11920-014-0490-8

Wang, S., \& Blazer, D. G. (2015). Depression and cognition in the elderly. Annual Review of Clinical Psychology, 11, 331-360. doi: 10.1146/annurevclinpsy-032814-112828

Werlang, B. S. G. (2012). Psychological Autopsy: an important strategy for retrospective evaluation. Ciência e Saúde Coletiva, 17(8), 1955-1957. doi: 10.1590/S1413-81232012000800003

(Article received: 10-09-2015; revised: 05-11-2015; accepted: 18-11-2015) 